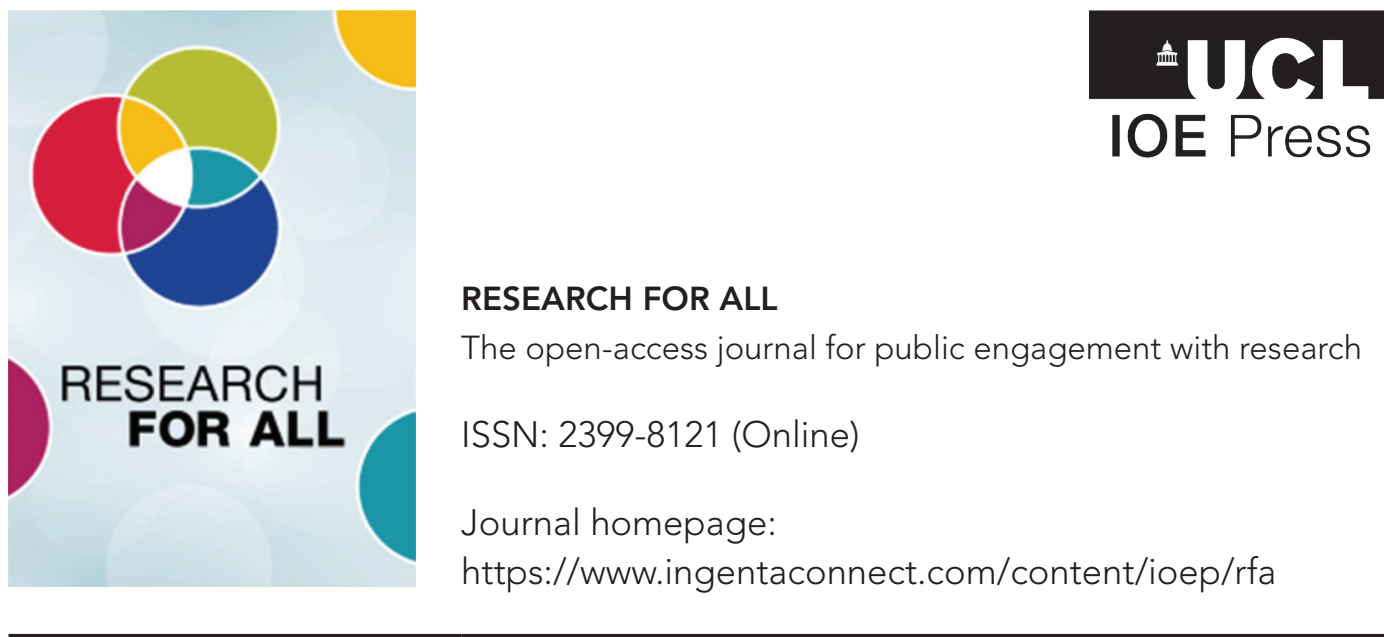

\title{
Tactile Collider: A new approach to the communication of fundamental science to visually impaired people
}

\author{
Rob Appleby (D), Chris Edmonds (iD) and Robyn Watson
}

\section{How to cite this article}

Appleby, R.B., Edmonds, C.S. and Watson, R. (2020) 'Tactile Collider: A new approach to the communication of fundamental science to visually impaired people'. Research for All, 4 (1): 16-32. DOI https://doi.org/10.18546/RFA.04.1.03

Submission date: 8 February 2019

Acceptance date: 17 October 2019

Publication date: 1 February 2020

\section{Peer review}

This article has been peer reviewed through the journal's standard double-blind peer review, where both the reviewers and authors are anonymized during review.

\section{Copyright}

(C) Copyright 2020 Appleby, Edmonds and Watson. This is an Open Access article distributed under the terms of the Creative Commons Attribution Licence (CC BY) 4.0 https://creativecommons.org/licenses/by/4.0/, which permits unrestricted use, distribution and reproduction in any medium, provided the original author and source are credited.

\section{Open access}

Research for All is a peer-reviewed open-access journal. 


\title{
Tactile Collider: A new approach to the communication of fundamental science to visually impaired people
}

Rob Appleby* - University of Manchester and the Cockcroft Institute, UK Chris Edmonds - University of Liverpool and the Cockcroft Institute, UK Robyn Watson - Bolton Sensory Support Service, UK

\begin{abstract}
There is a large public interest in topics such as the Large Hadron Collider and the Higgs boson, primarily communicated to school children and the wider public using visual methods. As a result, visually impaired audiences of all ages often have difficulty accessing the scientific communication and may not be culturally involved in the scientific process. Tactile Collider aims to address this issue and has developed new methods of engaging visually impaired children and adults in science by the creation of the Tactile Collider model. This model has been developed with visual impairment $(\mathrm{VI})$ experts and consultations, and implemented in a national touring event called Tactile Collider, visiting VI schools and centres around the country between 2017 and 2019. This paper describes the model and its development, and the use of the model to curate Tactile Collider events in 2017 and 2018. We present a quantitative and qualitative analysis of three 2018 events, showing the effectiveness of the approach and the engagement of the audience. The broader applicability is discussed.
\end{abstract}

Keywords: physics, accelerator physics, visual impairment, public engagement, communication

\section{Key messages}

- An iterative loop of audience, design and subject professional interactions led to seven principles for communicating STEM to visually impaired audiences.

- Training researchers in how to interact with people with a visual impairment, as well as educating them on a range of visual impairment conditions, helped to build confidence in engaging an audience with visual impairment with scientific content.

- The Tactile Collider model gives a firm foundation for communicating and engaging with audiences with visual impairment and is relevant to other underrepresented audiences. 


\section{Introduction}

The communication and outreach from the scientific community to the wider public is an important part of the scientific process, to inform the wider community and give engagement to all stakeholders. As such, wide communication is a responsibility and duty of every scientist. This effective communication also helps formal education and recruitment into science, technology, engineering and mathematics (STEM) subjects (QAA, 2017). However, this communication of the science is predominantly delivered using visual methods, often using pictures, conventional diagrams and other graphics (ibid.) to explain the material. This is due, in part, to the traditionally visual nature of the topic, very little available accessible science content, lack of scientist training and the inherent difficulty of the subject matter. As a result, visually impaired audiences of all ages often have difficulty accessing the scientific content and may not be as engaged as their sighted peers. This can result in the exclusion of large demographic groups (Mason, 2001; Fisher and Hartmann, 2005). Very often, scientists lack the specialist skills and materials required to make projects accessible to students with visual impairment $(\mathrm{VI})$, meaning that teaching assistants act as intermediaries in the interaction, diluting the impact. As well as the reduction in science capital of the large audience with $\mathrm{VI}$ (and other under-represented audiences), potential recruitment into STEM subjects is compromised. In this paper, we shall define visual impairment as some kind of sight loss, either partial or (less commonly) total sight loss. There are two million people in the UK with some kind of sight loss (RNIB, 2017), making this a very large underrepresented audience.

Tactile Collider (www.tactilecollider.uk) has addressed this deficit by developing a new model to communicate fundamental science to visually impaired audiences. The overall vision is to produce a learning experience that allows people with $\mathrm{VI}$ to participate fully in science education and improve scientific literacy (RNIB, 2017). The project team worked directly with members of the VI community and with VI professionals to ensure a high-quality, accessible and interesting approach, and to develop a successful communication model between the audience and the science. This, combined with the well-defined scientific learning outcomes and a careful analysis of primary and secondary audiences, has led to the development of the Tactile Collider model described in this paper. The model comprises seven principles for communication of STEM to the VI community, developed through the experience of Tactile Collider, showing that the model works in practice. The team has used the model in a series of events delivered to a $\mathrm{VI}$ audience, primarily in a school environment but also at festivals and other public spaces.

In this paper, we describe the development and principles of the Tactile Collider model. We also demonstrate how the model was used to curate the Tactile Collider event in 2017/18. Evaluation of the Tactile Collider event was performed by external evaluators against the expected learning outcomes to demonstrate the effectiveness of the model in reaching this audience.

The layout of this paper is as follows:

- principles of the Tactile Collider model, set out with a full discussion of its development

- event implementation, explaining how the model guides the event

- event case study and evaluation over three events in 2018, demonstrating the effectiveness of Tactile Collider to meet the anticipated primary audience outcomes. 
The result of the work is a communication model and a successful touring event that brings the science to the audience, changing the perception of science and science careers. This paper shows, through event evaluation, the success of the approach and concludes with comments on the wider applicability.

\section{Tactile Collider model}

In this section, we describe the development and principles of the Tactile Collider model, which was developed in 2017 and 2018 by a trained team of scientists, with audience participation and working with a large range of consultants in $\mathrm{VI}$ and communication. This process was done without preconceptions of the method of engagement, to ensure an engagement solution that matched audience needs and filled the deficit identified in the Introduction. The scientists in the project team were recruited from the Cockcroft Institute's PhD students, giving a focus on the STEM subjects. The key steps of the concept, model and event design process can be broken down to a process of audience engagement, training and event development, which we will now describe.

In the early phase of the project, time was taken to work with people with visual impairments to look at their varied ways of learning and accessing information. This included visits to VI-specialist schools to observe lessons, discussions with VIspecialist teachers and visits to schools to interact with students with a VI, of a variety of ages. The goal was to understand the learning process of the audience and understand how best to engage with the audience on their terms. Following this initial phase, specialist training was delivered to scientists at an early point in the project. The timing of this was key, as it allowed the resources and delivery methods to be developed with audience requirement as the main consideration. A key aspect of the project was that the content was developed specifically for an audience with visual impairments, so early training was essential to incorporate this into the development stage. Training the researchers in how to guide people with a VI (sight-guide), as well as educating them on a range of VI conditions, helped to build confidence and positivity in the project team. It also improved understanding of audience needs, as well as improving practical skills in engaging with the VI community. The science content and link to teaching syllabuses was only decided after the long phase of audience interaction and training. It was reached through dedicated meetings and with constant reference to the audience. This iterative loop of design, audience and $\mathrm{VI}$ professional interaction was the heart of the process. Specific training was done in advanced topics such as tactile map production, 3D design and printing, and audio description. The project materials were designed and produced after the training was complete. All materials were trialled with a selection of visually impaired students. The students had a range of abilities to ensure that all abilities were catered for. Feedback was gathered from both students and the team, which was used to refine the process. The prototype event, with all materials and scripts, was then tested on small groups of students with a VI and their teachers. The project team's skills were developed and honed through repeated delivery of sessions, with the materials and events themselves being developed in a continuous process of evolution. From the beginning of the project, the training of the researchers was a key priority. The scientists' enthusiasm and the interactive nature of the project created a successful learning environment where researchers, students and educators were comfortable and confident. 
The result of the training and pilot process gave rise to the Tactile Collider model (TCM), which brings seven broad principles for engagement with $\mathrm{VI}$ audiences. These principles were found to work during the process described and they resonated with the target audience. The TCM also has applicability to other audiences with disabilities, such as learners with autism or hearing impairments. The principles that guide the event and form the basis of the TCM are:

1. Authenticity. The science message and experience given to a VI audience should be in no way different to that given to a non-VI audience in content or depth. Materials need to be adapted to spread complexity across a number of different mediums, and the time taken to deliver content needs to be extended to allow the target audience time to engage with complicated theories and ideas. For example, visually communicated ideas on the Higgs boson, normally described using visual Feynman diagrams, should be communicated with tactile or audio versions of the same information. In the same way, authentic scientific language should be used where possible, with appropriate definitions and clarifications.

2. Interactivity. The needs of learners with VI require close interaction with a scientistpresenter in a group no larger than four participants. The presenter should be trained in VI awareness, sighted guiding and audio description, and in the presentation of a tactile narrative linked to the learning outcomes. This dialogue between the learner and the scientist is the core of the interaction model and, while requiring more time and training than conventional science communication, ensures that the science learning outcomes are communicated and the experience is tailored to the audience needs.

3. Multi-mode communication. The science learning outcomes for this audience should be communicated in several different ways, to accommodate varying degrees and impact of personal sight loss and the personal learning strategies that have evolved as a result. This multi-mode approach reinforces the key learning points (Bourne et al., 2017) and gives the learner the option of different methods. Note this is also a response to potential reluctance of the audience to reveal the details of a VI. For example, using a tactile diagram alongside a tactile object (Jones et al., 2006) and audio soundscape to explain the movement of particles in a particle accelerator, or the combination of a tactile object and a tactile diagram for the concept of a bar magnet.

4. Awareness of diverse audience needs. The range of visual impairments in the audience group is broad, with total sight loss uncommon and the requirements of text size and materials very person dependent. For example, modified large print, alongside Braille, is needed on all material. This awareness is essential for the presenter, and defines the mode of interaction, with a strong audience-led approach. The training of presenters for a project with an audience with $\mathrm{VI}$ is essential and core to success.

5. Extensive training and testing. The concept was developed over a year, with extensive consultation with $\mathrm{VI}$ experts and trainers, and testing on audience members. All events, materials, concepts and scripts for the audience with $\mathrm{VI}$ need extensive testing on small, receptive audience groups, and all scientists in contact with the audience need dedicated and specialist VI training in topics such as guiding, audio description and audience needs. 
6. Design and preparation. The need for small groups means that techniques such as 3D printing of materials can be uneconomical. All designs should be developed with mass production and dissemination in mind. For example, materials can be cast with plastic resin from silicon moulds produced from a 3D print.

7. CPD and the public. The primary audience of a Vl-focused event also encompasses teachers and teaching assistants who work alongside learners with a VI, who will be provided with dedicated continuing professional development (CPD) sessions aimed at increasing the expertise and knowledge of the teaching staff. This ensures buy-in from this group, effective training (and hence secondary impact) and longer-term dissemination. The public, defined as walk-in guests at events in public spaces such as museums, can also gain through interaction with the event.

These seven broad principles combine to form the Tactile Collider model, and serve as a guide to event design and delivery for a VI audience.

\section{The Tactile Collider event: An implementation of the model}

In this section, we discuss how an event, called Tactile Collider, was created using the TCM, allowing testing of the approach and quantitative evaluation with the target audience. Tactile Collider toured the UK and Europe between 2017 and 2019. It aimed to reach four main audiences, each of which had their own unique anticipated learning outcomes.

\section{The audiences of Tactile Collider}

The primary audience of Tactile Collider is young people aged 12 to 18 who are visually impaired. This is to address the difficulties in accessing science for this age group, and to encourage an interest in STEM subjects after the ages of 16 and 18. The learning outcomes for this audience were:

- they feel science is for them

- they feel more confident, empowered and knowledgeable about science

- they feel more confident, empowered and knowledgeable about particle and accelerator physics.

A key secondary audience was people who guide and mentor school students. This group are the educators of the young people with VI. This group includes the parents, carers, teachers and/or teaching assistants who provide careers direction and secondary impact after the contact time of Tactile Collider. The intended outcomes for the educators who attend the CPD sessions are:

- they believe that science is a valid option for young people with VI

- they are more open to trying new ways of engaging young people with science

- they have the skills to engage young people and the confidence to deliver science content.

This audience ensures the positive experience of the young people and maximizes event impact, and they are the reason for the CPD aspects of the event described later.

A third audience is the scientists involved in delivering the project. The outcomes for this group are: 
- they feel more confident and positive about making science accessible to students with access requirements

- they have developed more accessible ways of engaging people with science

- they have a working understanding of the ways that people with VI can be supported in a mainstream educational setting.

The training and development of young scientists enables later engagement with under-represented audiences.

Beyond engagement with students with $\mathrm{VI}$ and the people who support or work with them, the project targeted non-visually impaired audiences at festivals to communicate the science in an unexpected way and raise awareness of $\mathrm{VI}$ issues, the public engagement community, the science community, mainstream educators and adults who are visually impaired. All of these target groups have an impact from Tactile Collider through their own set of outcomes. The evaluation in this paper will focus on the primary audience, with some comment made on other audiences.

The Tactile Collider event is produced following the model described in this paper and focuses on the communication of the Large Hadron Collider (LHC) and the Higgs boson to the $\mathrm{VI}$ audience. The event follows the model principles and communicates four concepts: (1) everything is made of particles; (2) we use magnets to control particle beams; (3) how we perform acceleration; and (4) the Higgs boson. The event shows that the model can be implemented for the target audience. The event itself is built around the concept of four stations, corresponding to the four science areas of the project. Each of the stations has a set of learning outcomes and draws upon the full range of techniques and communication methods. The script for each station covers learning outcomes and the suggested use of the materials, while leaving the presenter free to interact naturally with the audience. The event is delivered in two parts, with 'particle' and 'magnet' stations in the first half, and 'acceleration' and 'Higgs' stations in the second half. The half-time break is an opportunity for a guided exploration of the $3.5 \mathrm{~m}$ tactile teaching particle accelerator called CASSIE.

The TCM was used to curate the event by carefully following its principles. The experience has authenticity (Principle 1, authenticity) as the material is created and delivered by real, trained scientists who work on particle accelerators and the Large Hadron Collider. The material was made through consultation with the audience (Principle 6, design and preparation). The content was the same as that delivered to a non-VI audience. The learners in the three evaluated events (see the next section) worked in a group, each of which had four school students and a PhD-student presenter. While the experience was guided with a script, the conversation was allowed to run freely (Principle 2, interactivity) while centring on the station learning outcomes. The materials for each scientific station were multi-mode (Principle 3, multimode communication), with a learner able to select the method that suited them best (Principle 4, awareness of diverse audience needs). For example, the Higgs boson station represented the physics of a Higgs boson using touch, sound and speech. The materials for the three events were tested extensively (Principle 5, extensive training and testing), both internally and in focus groups at our laboratory. The events also included public 'drop-in' events and teacher training (CPD) sessions (Principle 7, CPD and the public).

The team also developed drama activities for the introduction and half-time break of Tactile Collider events. These physical acts got the audience moving, broke down barriers and reinforced learning outcomes. The drama was developed with an 
external consultant specializing in embodied learning and with $\mathrm{VI}$ audience skills. The drama took the form of small groups of audience members performing pieces to the rest of the group, with a Tactile Collider team member audio describing. Note that the audio description of the performed pieces was essential.

\section{The four interactive stations}

The four stations break the content down into 20-minute interactive chunks, delivered by trained scientist-presenters. Students begin with the particle and magnet stations in the first half, before moving on to the acceleration and Higgs stations after the break. The stations' learning outcomes are described in Box 1.

\section{Box 1: Learning outcomes}

The learning outcomes of the particle station are:

- everything is made out of a set of very small fundamental particles

- these particles interact with each other through forces (exchanged particles)

- we have a theory - the standard model - that describes these particles and their interactions.

The learning outcomes of the magnet station are:

- the concept of a magnet, magnetic poles and attraction/repulsion of magnets

- controlling a beam with a magnet, bending (dipoles) and focusing (quadrupoles)

- building a ring with magnets.

The learning outcomes of the acceleration station are:

- what is acceleration: linear (and ring)

- accelerate using waves of energy

- create waves of energy with radio frequency accelerating cavities.

The learning outcomes of the Higgs station are:

- squeezing of the beam, beam envelopes

- detectors and collisions

- Higgs and Higgs events.

All stations included a range of tactile diagrams, and three stations included 3D soundscapes of sonified accelerator and Higgs sounds delivered using headphones (called Sonic Collider). Full details of station content and pictures can be found on the Tactile Collider event website and repository page (www.tactilecollider.uk).

The particle station aims to communicate the particle content of the universe and how these fundamental particles build atoms and molecules. In this station, materials were developed such as particle sorting games, tactile diagrams and tactile models to explain the size and structure of particles. The magnet station communicates the concept of a magnet, and how magnets are used to bend and focus particle beams in particle accelerators. In this station, materials were developed to build up the ideas of magnets, dipoles, quadrupoles and magnetic lattices. The concept of a tactile magnet was central to this station. The acceleration station communicates what acceleration is and how we use electric fields in cavities to accelerate charged particles. In this station, materials were developed such as static electricity games, tactile models and maps of cavities. The Higgs station communicates the idea of the Higgs boson and observation using particle detectors. In this station, materials were developed such as tactile real 
Higgs decay events from the LHC, jigsaws of particle detectors from the LHC, models of real detectors and tactile diagrams.

\section{The tactile teaching particle accelerator: CASSIE}

The Tactile Collider event is built around interaction between scientists and learners in small groups. CASSIE is a $3.5 \mathrm{~m}$ diameter portable tactile accelerator (Conceptual Accelerator Setup Supporting Inclusive Education), a model of the LHC that the event brings to a $\mathrm{VI}$ audience who may struggle to come to a laboratory such as Daresbury or CERN.

\section{Continuing professional development}

The need for CPD was highlighted by the TCM; therefore, a robust and comprehensive plan was developed. Everything needs to be based on the model. These CPD sessions covered the science presented and the methods of presenting. This supported the specialist teachers and increased the impact of the events. Teacher packs, downloadable from the Tactile Collider website (www.tactilecollider.uk), enabled the material to be taught independently of the Tactile Collider team.

\section{An event case study and evaluation}

The TCM and the implementation were largely developed in 2017, and events based on the TCM were delivered across the UK from 2018. In this section, we examine one of these events, discuss the evaluation strategy for the three audiences and present the results of this evaluation.

\section{The Glasgow Tactile Collider event 2018}

An event delivered at a Glasgow secondary school on 13 June 2018 by a team of eight scientists is presented as a case study. During earlier research, we had found that many young people with $\mathrm{VI}$ attend mainstream schools but are often removed from science lessons to receive specialist support. For young people in mainstream schools we operate hub events, where we invite young people with VI from across the region. (Regional sensory support services helped us to identify these children.) The Glasgow event was an example of this hub approach. The audience for the event was 30 students with $\mathrm{VI}$ and 9 teachers, who attended one of two sessions (morning or afternoon). Each session was two hours long, and evaluation data were collected at the start and end of each session.

When students and teachers arrived, they were taken to a reception room. Here they completed pre-event questionnaires and were divided into four groups (four or five people per group). The groups then joined the scientists in the main room, where each scientist briefly introduced themselves. Two groups joined the particle stations and two groups joined the magnet stations (there were two of each station). The scientist running the station has a set of learning outcomes and a sample script they can follow, but prioritizes responding to the audience's needs. For example, for young people with no vision, tactile maps are used, or in cases where a young person has severe learning difficulties, a sensory-based experience is created. After 20 minutes, the students who were at the particle station swap to the magnet station and vice versa. 
After the young people completed these two introductory stations, they were invited to explore CASSIE in a student-led experience designed to reinforce learning. The CASSIE model puts the magnet and particle station content into the wider context of accelerators. Scientists are on hand to answer any questions.

The second half involved two slightly shorter stations - acceleration and Higgs. After these, the entire group was brought back together for an embodied learning session, with young people acting out sentences such as 'dipole magnets are used to steer particle beams in the LHC'. The session ended with a close-out, and with young people and teachers completing the evaluation feedback. After a short break the second set of students arrived, and the session was repeated.

\section{Evaluation methodology}

Evaluation was performed to assess the achievement of the intended outcomes described above.

Separate evaluation methods were developed for each of the identified audiences, following a focus group with independent professional evaluators. The same evaluators implemented the evaluation, collecting data for young people and educator audiences across three Tactile Collider events (which took place in schools in Hereford, Edinburgh and Glasgow) and from the project scientists after these three events.

The approach taken had a mixed methodology, with both quantitative and qualitative data collected. The data were collected through:

1. Short before and after questionnaires, with a Likert scale response (from 1 strongly disagree, to 5 -strongly agree) to five statements. The questionnaires were designed to provide all young people with the same experience of responding (without the assistance of an additional person). A paper system that included different print sizes and Braille was initially devised and used at the first event, but was subsequently replaced by an online system to better accommodate the needs of the audience.

2. One-to-one interviews with young people in the project directly after the event. These interviews set out to provide some basic insight into why the young people responded to questionnaires as they did. Young people who took part in one-toone interviews were asked questions early in the interview to establish whether their attitudes towards science were negative, neutral or positive (referred to as science-negative, science-neutral or science-positive).

3. Ethnographic observations at Tactile Collider sessions. The evaluators observed sessions, noting how the young people behaved, how the scientists (and others) engaged with them, the environment and the atmosphere. These observations helped in interpreting data gathered through questionnaires and interviews.

4. Post-session questionnaires with educators, focusing on open-ended questions asking about individual experiences of the session.

5. One-to-one interviews with the Tactile Collider team: telephone interviews with team members after the three Tactile Collider sessions that are evaluated in this article. These interviews sought to evaluate the learning and development of the team members and how they feel about making science more accessible in future. 
Table 1 provides an overview of the number of responses collected for each of the methods listed above.

\section{Table 1: Responses to evaluation}

\begin{tabular}{ll}
\hline Audience/methodology & Data gathered \\
\hline $\begin{array}{l}\text { Young people: before/after } \\
\text { questionnaire }\end{array}$ & $\begin{array}{l}52 \text { complete responses gathered at three events; total of } \\
64 \text { participants (incomplete responses were filtered out) } \\
\text { Young people: } 121 \text { post-event } \\
\text { interviews }\end{array}$ \\
$\begin{array}{l}\text { Teachers/teaching assistants/ } \\
\text { parents: post-event }\end{array}$ & 26 responses; total of 36 participants \\
questionnaire & \\
$\begin{array}{l}\text { Tactile Collider team/ } \\
\text { participants: ethnographic } \\
\text { observations }\end{array}$ & 4 observations completed \\
Project team: 121 interviews & 8 interviews, from a total of 11 team members \\
\hline
\end{tabular}

Many of the incomplete responses for the before/after questionnaires were collected at the first session, where paper-based data collection methods were used. The shortcomings of this approach led to a digital system being used for the second and third sessions, with the survey designed using the Web Content Accessibility Guidelines 2.1. The questionnaire was formatted to allow text-to-speech software to read the questions aloud without issue. The young people were offered a range of different ways of completing the questionnaire: using a link on their own mobile devices, using a tablet PC that we provided or having the questionnaire read to them by an evaluator.

An observation framework was drawn up, which the evaluators used in the sessions. The framework gave structure to the observations, meaning that the same aspects of the sessions were considered each time, as well as leaving space for other incidental observations.

\section{Outcomes: Young people}

The outcomes of the young people's quantitative evaluation are reported first. The young people's questionnaire consisted of three before/after questions and two questions asked solely after. The questions that were asked at the start and end of the session aim to investigate changes in attitudes towards science that may lead to improved science literacy and greater participation in science communication. This is linked to the audience outcomes discussed above. The responses of the before/ after questionnaires (Figure 1) indicate that most young people held positive attitudes towards science, science learning and talking about physics with their friends by the end of the session. 
Figure 1: Charts demonstrating young people's changes in attitude towards science over a Tactile Collider session: respondents were asked before and after the session to what extent they agreed with three statements

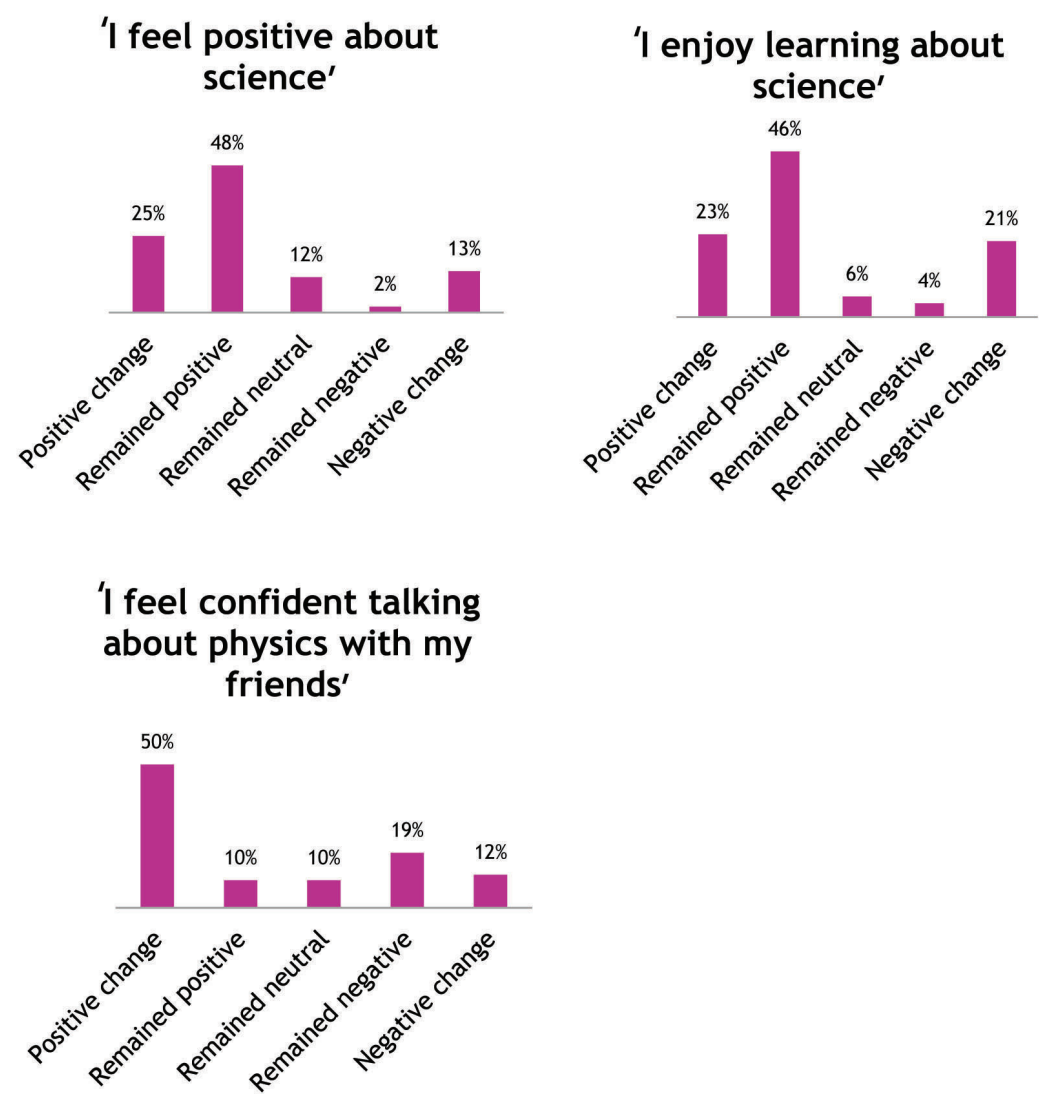

Young people also responded to the statements 'Tactile Collider has inspired me to learn something new about physics' (Figure 2) and 'Tactile Collider has helped me to learn something new about physics' (Figure 3). It was found that 69 per cent and 73 per cent respectively either strongly agree or agree with the statements.

Figure 2: Chart showing audience response to the statement 'Tactile Collider has inspired me to learn more about physics'

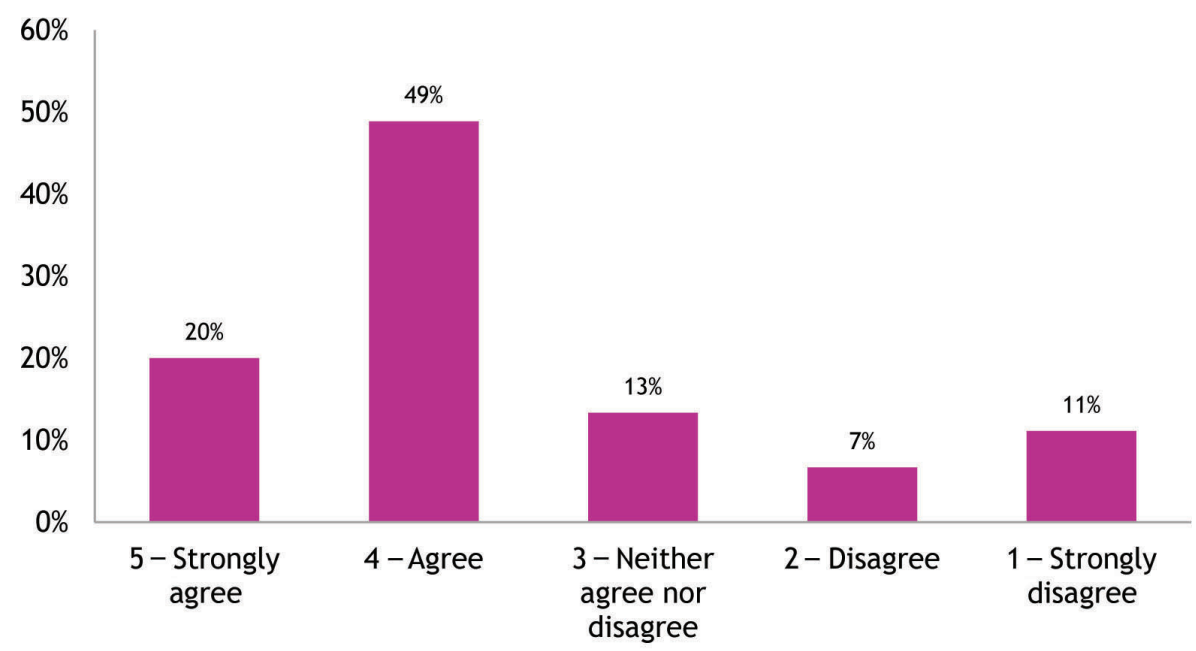



Figure 3: Chart showing audience response to the statement 'Tactile Collider has
helped me learn something new about physics'

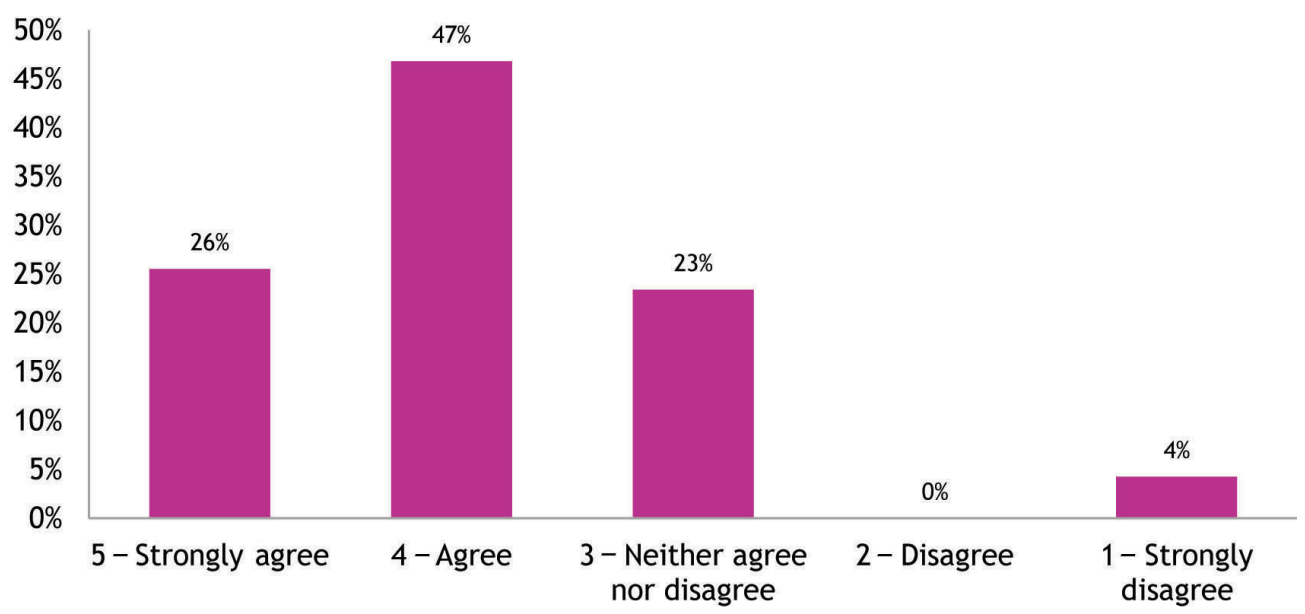

In Figure 1 we see that for some young people there were negative changes in attitude, especially for the statement 'I enjoy learning about science'. The young people's responses to these questions were anonymous and not linked to the one-to-one interviews. Furthermore, there had been no negative responses during one-to-one interviews. These two factors mean that the current evaluation offers no further avenue for understanding why some attitudes changed negatively; a modified evaluation method will be used for a future longitudinal study.

The qualitative data do offer insight into why attitudes may have changed positively. An 18-year-old girl from Glasgow (identified as being science-negative) said, when discussing her experience of science at school, 'I couldn't get it, I felt really stupid.' The same student said of Tactile Collider that while she did not understand all of the science, she did have a positive experience: 'the fun, down-to-earth environment ... It was more fun than a science class.'

Several young people reflected on the differences between Tactile Collider and other learning experiences that they had encountered. A second 18-year-old girl (science-negative) from Glasgow said: 'You're actually shown things, this really worked. It gives you a better grasp than being told things, you're actually experiencing it.' A 17-year-old boy (science-positive) from Hereford compared Tactile Collider to museums: '[Tactile Collider is] a lot better. In museums you don't really get to touch stuff ... you can't really get involved. You could get up close and personal.' Some of the young people with $\mathrm{VI}$ had referred to the difficulties of learning science in a classroom, describing feelings of anxiety surrounding using Bunsen burners and worrying about knocking equipment over. Tactile Collider offers a more relaxed and accessible environment due to its special design, which is inclusive of people with VI.

Although not asked this directly, many young people saw their interactions with the Tactile Collider team as a highlight. One 18-year-old girl (science-negative) from Glasgow said: 'The scientists were really welcoming, they were really down to earth and funny and welcoming.' A 16-year-old girl (science-positive) from Edinburgh said: 'I really loved talking to the scientists, it was the high spot for me. They were really easy to talk to, and encouraging.'

Despite the age range of participants, the differences in levels of academic ability, levels of interest in science and different visual impairments, many interviewees repeatedly (and without prompting) talked about the level of the sessions being 
'just right'. Important components to this success include presenters being trained to recognize and quickly respond to the support needs of their audience, as well as having appropriate resources to support these interactions.

Overall, the data and analysis of the primary audience - young people who are visually impaired aged 12 to 18 - show the effectiveness of the model and its implementation in 2018 to meet the intended learning outcomes. For some young people, Tactile Collider has made science seem more accessible. As one 13-year-old boy (science-positive) from Hereford said, 'Now that I've been here and I know there is a way of doing it [science] that is more accessible.'

\section{Outcomes: Educators}

The educators who encountered Tactile Collider were also positive about the experience. A teacher from Bradford summarized the event:

A couple [of students] have already said they wanted to do science but were worried about whether it was accessible ... they now feel it is. This shows ... that science is accessible for them ... they realize that university can be for them. It's empowering for the students to see things can be made accessible, it models best practice for teaching assistants and teachers. The students have realized what can be done if people can be bothered. Some of the young people now feel more confident asking for large print in school.

Empowering some students to feel more confident to ask for modified work within their school or college was an unintended but powerful outcome of Tactile Collider.

Teachers felt that the multimodal and student-centred approaches to the sessions were appropriate. A teacher from Bradford said: 'Great variety of tactile/audio resources meant that students could be involved throughout - too often VI students are peripheral to the science lesson.'

Teachers also felt that the session inspired confidence in the way that they present materials to their students. A teacher from Glasgow said:

I feel more confident in supporting young people, particularly those with a visual impairment, in science. It has inspired me to be more creative in the way I present science and describe difficult concepts in a way that is easy for pupils to understand.

Teachers also recognized that the methods used were relevant to all students (not just those with $\mathrm{VI}$ ) and could be used to build a more inclusive classroom. Further, teachers from non-physics backgrounds felt that the approaches would transfer well to their subject disciplines. A teacher from Bradford said: 'As a biology science teacher this has given me loads of ideas and [I] feel more confident in this area.'

\section{Outcomes: Tactile Collider team}

The Tactile Collider presenters are predominantly made up of accelerator science PhD students. We recognize this audience as being the educators of tomorrow. The presenters were aware of the importance of public engagement work, with one student saying: 'If we can't tell people about what we're doing then that means we're not doing a good job or [it is] not as worthwhile. Being able to explain it to people is important.' 
Many PhD students reported being apprehensive at the beginning of the project, but that they gained confidence following the training and initial sessions. The apprehension partly came from working with a new under-represented audience that the presenters themselves did not represent. One presenter commented to the evaluators: 'When you're not used to being around blind people ... you're always worried that you're going to do the wrong thing.' The training served to provide the presenters with relevant experience of some of the day-to-day issues with which people with VI deal. A presenter said it was 'good to learn what it's like to be visually impaired, it helps you consider all the things you hadn't thought about before'. The training also introduced visual impairment as a spectrum of conditions, leading to awareness in the presenters that 'solutions were not one size fits all'.

A legacy of the project may be a set of researchers who are more confident in engaging new audiences with science, who can recognize their shortcomings in engaging with this audience and who are aware of the steps necessary to build an effective learning experience. The presenters themselves recognized these attributes of a good communicator, with one student saying: 'You learn to describe in words what's happening. You learn to be observant, it's an interesting skill we learnt, useful in all aspects of your life. It makes you observant, patient and accurate.'

\section{Conclusion and outlook}

The way science is currently presented often relies on visual methods, excluding the large and largely underserved visually impaired audience. In this paper, we have presented a new approach to scientific communication and teaching of science and engineering to this audience, developing the Tactile Collider model. This has been developed with $\mathrm{VI}$ experts and consultations over a long period of time and gives seven principles for communication of science to this audience. The model was used to create an interactive experience called the Tactile Collider event. The event visited VI schools and centres around the country from 2017 to 2019, and communicated the science of the Large Hadron Collider and the Higgs boson. We described the event and a specific case study where external evaluation was performed. The evaluation shows a positive change in key questions posed to the audience before and after the event, and we conclude that the Tactile Collider event is effective in reaching this audience and making an accessible event. The careful event development based on the TCM resulted in an audience that was demonstrably more engaged and enthused. The outcomes are linked to scientific literacy, and the longitudinal impact on literacy would be a valuable follow-up study.

The key messages of this work are:

- an iterative loop of audience, design and subject professional interactions led to seven principles for communicating STEM to visually impaired audiences

- training researchers in how to interact with people with a visual impairment, as well as educating them on a range of visual impairment conditions, helped to build confidence in engaging an audience with visual impairment with scientific content

- the Tactile Collider model gives a firm foundation for communicating and engaging with audiences with visual impairment and is relevant to other underrepresented audiences. 
It is interesting to draw parallels to the closely aligned excellent project Tactile Universe at Portsmouth's Institute of Cosmology and Gravitation (https://tactileuniverse.org), which grew independently of Tactile Collider and targets the same audience for the communication of astronomy, albeit with a differing approach.

This model is applicable to many areas of science communication, due to its consideration of the fundamental method of engagement. The accessible format established by the model is also applicable to other underserved audiences. For example, the model gives a solid base for engaging with audiences with other disabilities and learning difficulties. The model can also be used in static museum implementations - the touring event described here is only one possible realization.

Finally, we are happy to work and discuss with any teams looking to reach underrepresented audiences, to pass on expertise and develop new approaches.

\section{Acknowledgements}

We wish to acknowledge the work and enthusiasm of all the participants, staff and students in Tactile Collider. Without them, nothing would have been achieved. We would also like to thank the Science and Technology Facilities Council (STFC) for funding Tactile Collider, especially Elizabeth Cunningham, Andy Thompson and Derek Gillespie. Finally, we would like to thank The Audience Agency, particularly Maya Sharma for a complete and professional evaluation. Tactile Collider is funded from STFC grant number ST/P000215/.

\section{Notes on the contributors}

Dr Rob Appleby is a reader in accelerator and particle physics at the University of Manchester and the Cockcroft Institute, UK. An expert on particle accelerators, Rob is the spokesperson and principal investigator of HL-LHC-UK, delivering the UK's contribution to the high luminosity upgrade of the LHC. He has been interested in public engagement and communication since 2004, including working with authors and film-makers, and with the use of music and sound to communicate science. In 2016 he created Tactile Collider, which has created new ways to communicate with underrepresented audiences.

Dr Chris Edmonds joined University of Liverpool and the Cockcroft Institute in 2010 as a researcher into particle accelerator physics, and now focuses on physics education and methods for engaging diverse audiences with science. As part of this role, he develops innovative educational programmes for undergraduate courses, which take influence from a strong interest in student-centred learning approaches and experiences from public engagement work. Chris leads several large public engagement projects.

Robyn Watson is a qualified teacher of the visually impaired with Bolton Sensory Support Service. She taught science in mainstream secondary schools before progressing to work with students with visual impairments. She currently works with young people from reception class through to postgraduate level in a variety of subjects. Robyn values outreach work and regularly organizes trips involving exciting activities designed to broaden student experience. She has been involved with Tactile Collider since January 2017. 


\section{References}

Bourne, R.R.A., Flaxman, S.R., Braithwaite, T., Cicinelli, M.V., Das, A., Jonas, J.B., Keeffe, J., Kempen, J.H., Leasher, J., Limburg, H., Naidoo, K., Pesudovs, K., Resnikoff, S., Silvester, A., Stevens, G.A., Tahhan, N., Wong, T.Y. and Taylor, H.R. (2017) 'Magnitude, temporal trends, and projections of the global prevalence of blindness and distance and near vision impairment: A systematic review and meta-analysis'. Lancet Global Health, 5 (9), e888-97. Online. https://tinyurl.com/y2sun4hd (accessed 30 October 2019).

Fisher, S.P. and Hartmann, C. (2005) 'Math through the mind's eye'. Mathematics Teacher, 99 (4), 246-50.

Jones, M.G., Minogue, J., Oppewal, T., Cook, M.P. and Broadwell, B. (2006) 'Visualizing without vision at the microscale: Students with visual impairments explore cells with touch'. Journal of Science Education and Technology, 15 (5), 345-51.

Mason, H. (2001) Visual Impairment. 2nd ed. Tamworth: NASEN.

QAA (Quality Assurance Agency for Higher Education) (2017) Subject Benchmark Statement - Physics, Astronomy and Astrophysics. Gloucester: Quality Assurance Agency for Higher Education.

RNIB (Royal National Institute of Blind People) (2017) The State of the Nation Eye Health 2017: A year in review. London: Royal National Institute of Blind People. Online. https://tinyurl.com/y5x66cg8 (accessed 30 October 2019). 